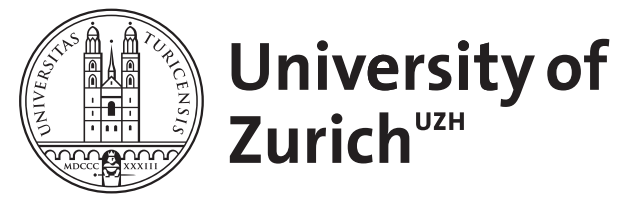
Archive

University of Zurich

University Library

Strickhofstrasse 39

CH-8057 Zurich

www.zora.uzh.ch

Year: 2019

\title{
Noninvasive Ventilation for Chronic Hypercapnic Respiratory Failure
}

Randerath, Winfried J ; Bloch, Konrad E

DOI: https://doi.org/10.1159/000492373

Posted at the Zurich Open Repository and Archive, University of Zurich

ZORA URL: https://doi.org/10.5167/uzh-179424

Journal Article

Published Version

Originally published at:

Randerath, Winfried J; Bloch, Konrad E (2019). Noninvasive Ventilation for Chronic Hypercapnic Respiratory Failure. Respiration, 97(1):1-2.

DOI: https://doi.org/10.1159/000492373 


\title{
Noninvasive Ventilation for Chronic Hypercapnic Respiratory Failure
}

\author{
Winfried J. Randerath ${ }^{a}$ Konrad E. Bloch ${ }^{b}$ \\ ${ }^{a}$ Krankenhaus Bethanien, Klinik für Pneumologie und Allergologie, Solingen, Germany; ${ }^{b}$ Pulmonary Division and \\ Sleep Disorders Centre, University Hospital Zurich, Zurich, Switzerland
}

Since its introduction into clinical practice a few decades ago, noninvasive positive pressure ventilation (NIV) has shown a triumphal advance with applications in a broad range of settings including anesthesia and perioperative care, critical care, respiratory and sleep medicine. Major reasons for this success are patient related, i.e., improved outcomes in terms of mortality, morbidity, need of hospitalization and, hence, quality of life. This is due to the avoidance of invasive airway instrumentation, no need for sedation and muscular relaxation, and the opportunity to apply NIV intermittently allowing for communication, oral fluid and food intake during breaks, or application of NIV predominantly during nocturnal sleep, which facilitates social integration of many patients with chronic hypercapnic respiratory failure. Constantly evolving technical advances such as the development of novel, powerful turbines for pressure and flow generation by light-weight, portable devices, sophisticated software supporting control of NIV as well as convenient and comfortable patient interfaces are also essential for the ongoing progress of NIV. A large number of innovative studies have helped to better understand the mechanisms of action of NIV in different settings and the key factors responsible for its clinical success. Although, in some areas,

\section{KARGER}

() 2018 S. Karger AG, Basel

E-Mail karger@karger.com

www.karger.com/res early applications of NIV by enthusiastic clinicians have run ahead of an evidence-based corroboration of its efficacy, ongoing research is continuously filling many of these gaps.

In view of the many advances in one particular field of NIV, i.e., its use in patients with chronic hypercapnic respiratory failure, which is important for respiratory, critical care, and sleep physicians alike, we have launched the current Thematic Review Series. The purpose is to provide the readers of Respiration a current update on selected topics with new developments and trends in this rapidly evolving field. Thus, one article will highlight the pathophysiology of chronic respiratory failure which may be caused by a combination of altered mechanics and gas exchange in lung and chest wall disease, respiratory muscle weakness of various etiologies, and alterations in neural control of breathing. Chronic respiratory failure may also be associated with instability of control of breathing leading to a periodic breathing pattern with frequent central apneas/hypopneas. Effective treatment may require

Prof. Winfried J. Randerath

Krankenhaus Bethanien, Klinik für Pneumologie und Allergologie

Aufderhöherstrasse 169-175

DE-47699 Solingen (Germany)

E-Mail randerath@klinik-bethanien.de

Prof. Konrad E. Bloch

Pulmonary Division and Sleep Disorders Centre, University Hospital Zurich

Rämistrasse 100

CH-8091 Zurich (Switzerland)

E-Mail konrad.bloch@dim.usz.ch 
an individual patient-tailored approach using specific NIV modes that are discussed in the Thematic Review Series. Recent trials have generated new evidence on the use of NIV in patients with chronic obstructive lung disease associated with chronic hypercapnic respiratory failure. These results will be critically reviewed to guide successful application of NIV in an area that has long been controversial. A further particular focus is put on a relatively new application of NIV, the ventilatory support during rehabilitation, which should allow patients to better regain mobility and independence in everyday life. Although the main purpose of NIV, supporting inspiratory muscles to enhance alveolar ventilation, is technically feasible in the majority of conditions, the sustained, successful application is often compromised by practical hindrances related to the patient-ventilator interface, monitoring of efficacy and side effects, and other practical aspects addressed in a particular contribution.
With major advances in medicine, the number of older patients with more severe and longer-term conditions requiring NIV and other therapeutic support prolonging survival is rapidly growing. Questions arise, which patients may really benefit not only in terms of immediate physiological success but in terms of improvement in symptoms and quality of life in the long term. Ethical considerations gain increasing importance when making treatment recommendations to patients with advanced, chronic conditions and these also need a critical discussion.

We are convinced that the different contributions to this Thematic Review Series on NIV by an international group of authors will provide scientifically sound and clinically useful insights to the readers that may assist in the selection and practical application of this valuable and highly effective treatment modality for patients with various forms of chronic hypercapnic ventilatory failure. 